\title{
Sea Breeze Damage Estimation Method using Sentinel of Remote Sensing Satellite Data
}

\author{
Kohei Arai \\ Faculty of Science and Engineering \\ Saga University, Saga City, Japan
}

\begin{abstract}
Sea breeze damage estimation method using Sentinel of remote sensing satellite data is proposed. There are two kinds of sea breeze damage. Namely, one is vegetation degradation due to sea salt from sea breeze and the other one is leaf lodging due to strong winds from sea breeze. Kyushu, Japan had severe storm due to the typhoon \#17 during from 21 September to 23 September 2019. Optical sensor and Synthetic Aperture Radar: SAR onboard remote sensing satellite are used for disaster relief. NDVI and false colored imagery data derived from the Sentinel-1 and 2 data are used for disaster relief. Through experiments, it is found that sea salt damage on rice paddy fields in particular can be relieved by NDVI and false colored imagery data while rice lodging can also be relieved by SAR data.
\end{abstract}

Keywords-Sentinel; disaster relief; satellite remote sensing; flooding; oil spill; synthetic aperture radar; optical sensor; vegetation index

\section{INTRODUCTION}

A large and strong typhoon \#17 traveled north from Okinawa in the East China Sea, and approached Kyushu on September 22 in 2019 and advanced from the vicinity of the Tsushima Strait to the Sea of Japan.

According to the Saga Local Meteorological Observatory, if Typhoon \#17 moved near the center of the forecast circle, Saga Prefecture entered a strong wind area with a wind speed of 15 meters or more by the early of the $22^{\text {nd }}$ of September. On the evening of the same day, it entered a storm zone with a wind speed of 25 meters or more and approached most early in the night. As the typhoon approached, warm and humid air flowed in and the air condition became extremely unstable. There was a very heavy rainfall, and there was also a risk of lightning, tornadoes and other severe gusts. The expected rainfall was $50 \mathrm{~mm}$ per hour in many places and $200 \mathrm{~mm}$ in 24 hours.

According to the Agricultural Administration Bureau, the cultivated area of rice in the prefecture is 24,100 hectares, the yield has dropped to 71,800 tons, $56 \%$ of last year, and more than $30 \%$ of non-standard rice is generated. Yield per 10 Ares was $298 \mathrm{~kg}$, down $234 \mathrm{~kg}$ from last year. The reason was that the number of spikelets and firs decreased in early July and late July due to low temperatures and lack of sunshine, but this was due to the salt damage caused by Typhoon \#17 in September and the damage caused by insect pests, brown planthoppers.

The crop index 58 was even lower than 86 in Kyushu as a whole. In each district, Matsuura is 79 and Saga is 53.
According to the Bureau of Agriculture, typhoon \#17 caused winds to blow north from the Ariake Sea, causing salt damage to spread mainly along the coast.

There are two major influencing disaster induced by typhoon, heavy rain and severe wind. Heavy rain is major cause of flooding, landslide, etc. while severe wind is major cause of storm surge, sea breeze, sea salt damage, lodging and so on. These disaster can be detected with remote sensing satellite based mission instruments, visible to near infrared radiometer, short wave infrared radiometer, thermal infrared radiometer, microwave radiometer, and Synthetic Aperture Radar: SAR and so on.

Previously, the method for estimation of sea salt amount attached to rice leaves with remote sensing satellite data is proposed [1]. Validation and confirmation of the proposed method, however, are not enough. In this regards, additional confirmation on effectiveness of the remote sensing satellite data for estimation of damage grade due to sea salt derived from typhoon sea breeze is conducted in this paper.

In order to relief disaster occurred areas, Sentinel-1 and 2 satellites based Visible to Near InfraRed: VNIR radiometer and SAR are used. Through comparison of the VNIR and SAR imagery data derived from Sentinel-1 and 2 satellite based instruments between before and after disaster occurrence, these disaster can be detected, in general. It is relatively easy to detect landslide, flooding, etc. because ground cover targets may change in particular vitality of vegetation while storm surge, sea breeze, sea salt damage and lodging are not so easy to detect. In particular, rice lodging causes a small vegetation vitality changes while backscattering coefficient of the vegetated areas may change due to rice lodging. Therefore, a method for sea salt damage area estimation is proposed by using VNIR imagery data together with a method for rice lodging damage area estimation by using SAR imagery data in this paper.

The next section describes related research works followed by the research back ground of this study. Then, experimental results are described followed by conclusions together with some discussions.

\section{RELATED RESEARCH WORKS}

There are some related studies on disaster relief and mitigation research works, Method for estimation of damage grade and damaged paddy field areas sue to salt containing sea breeze with typhoon using remote sensing imagery data is proposed and validated [1]. Four dimensional GIS and its 
application to disaster donitoring with satellite remote sensing data is proposed in the Conference on GIS and Application of Remote Sensing to Disaster Management [2], [3].

Meanwhile, URL search engine with text search tools for disaster mitigation is proposed in the Asian Disaster Reduction Center R\&D Project Workshop [4]. On the other hand, visualization of disaster information derived from Earth observation data is proposed [5]. Also, ICT technology for disaster mitigation, tsunami warning system is proposed in the 1st International Workshop on Knowledge Cluster Systems [6]. In the same time, cellular automata approach for disaster propagation prediction and required data system in GIS representations is proposed in the 1st ICSU/WDS Conference Global Data for Global Science [7].

Meantime, cell based GIS as Cellular Automata: CA for disaster spreading prediction and required data systems is proposed in the CODATA Data Science Journal [8] together with disaster relief with satellite based synthetic aperture radar data [9]. Meanwhile, Sentinel 1A SAR data analysis for disaster mitigation in Kyushu is presented [10]. On the other hand, Sensor network for landslide monitoring with laser ranging system avoiding rainfall influence on laser ranging by means of time diversity and satellite imagery data based landslide disaster relief is proposed and validated [11].

Quite recently, flooding and oil spill disaster relief using Sentinel of remote sensing satellite data is reported [12],

\section{REASEARCH BACKGROUND}

On the morning of September 22, the typhoon \#17 hits Japanese vicinity. Fig. 1 shows the trajectory of the typhoon \#17. Starting from southern sea area of Okinawa, to the center of the Japan Sea, typhoon \#17 traveled with strong wind and heavy rain. At around 9 a.m. on September 23, the typhoon was changed to temperate cyclone.

Fig. 2(a), (b), and (c) show atmospheric pressure maps and geostationary meteorological satellite MTSAT (Japanese Meteorological Satellite in the geostationary orbit) images observed at 3:00 (UTC) on 21, 22, and 23 September 2019, respectively.

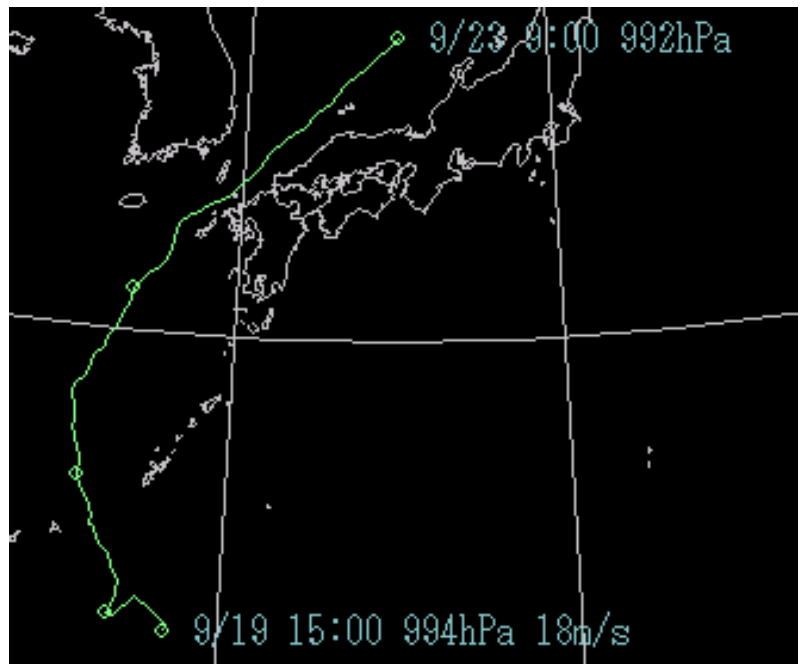

Fig. 1. Trajectory of the Typhoon \#17.

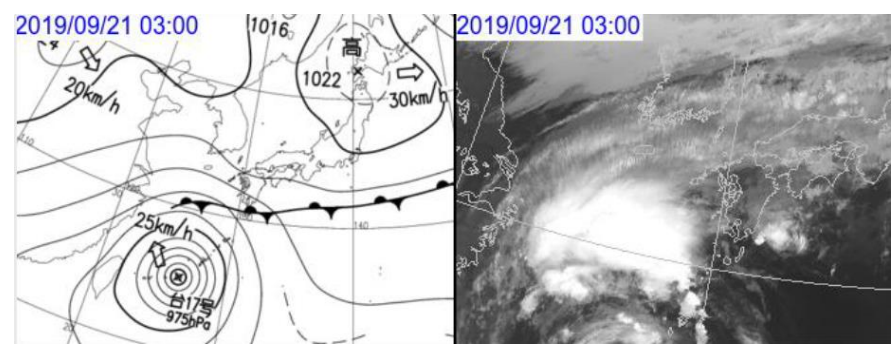

(a) 21 September.

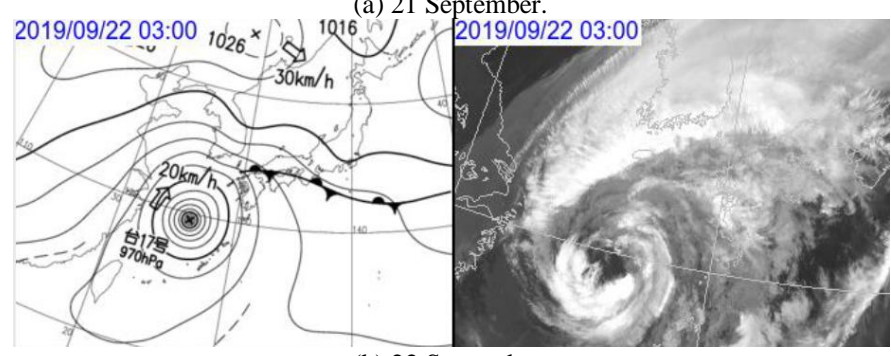

(b) 22 September.

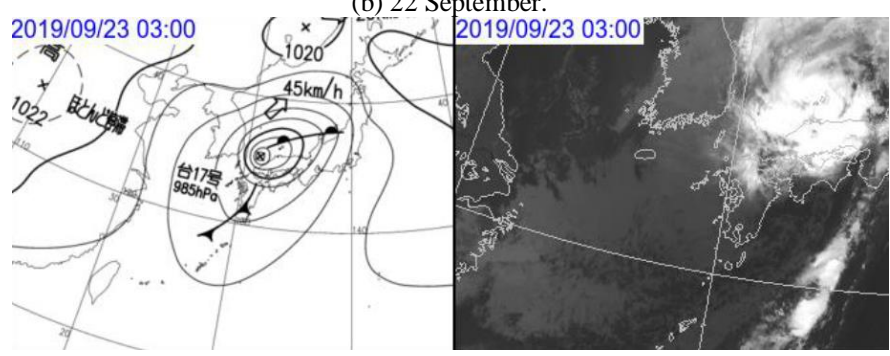

(c) 23 September

Fig. 2. Atmospheric Pressure Maps and Geostationary Meteorological Satellite Images Observed at 3:00 (UTC) on 21, 22, and 23 September 2019

In particular at 12:00 (JST), noon on 22 September, Kyushu Japan had a heavy rain and a severely strong wind as shown in Fig. 3. Elapsed time of the maximum wind speed and the momentary maximum wind speed are shown in Fig. 4(a) and (b), respectively.

Although rainfall rate of the typhoon \#17 is not so heavy, wind speed of the typhoon \#17 is extremely high. Due to the severely strong wind shown in Fig. 4, sea salt damage and rice lodging are occurred in Kyushu, Japan.

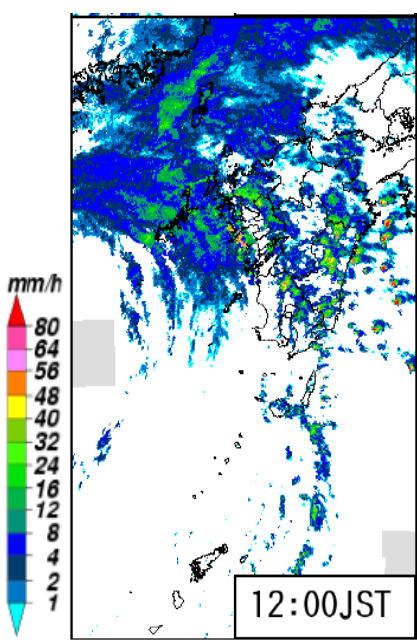

Fig. 3. Heavy Rain and a Severely Strong Wind at 12:00 (JST), Noon on 22 September, Kyushu Japan. 


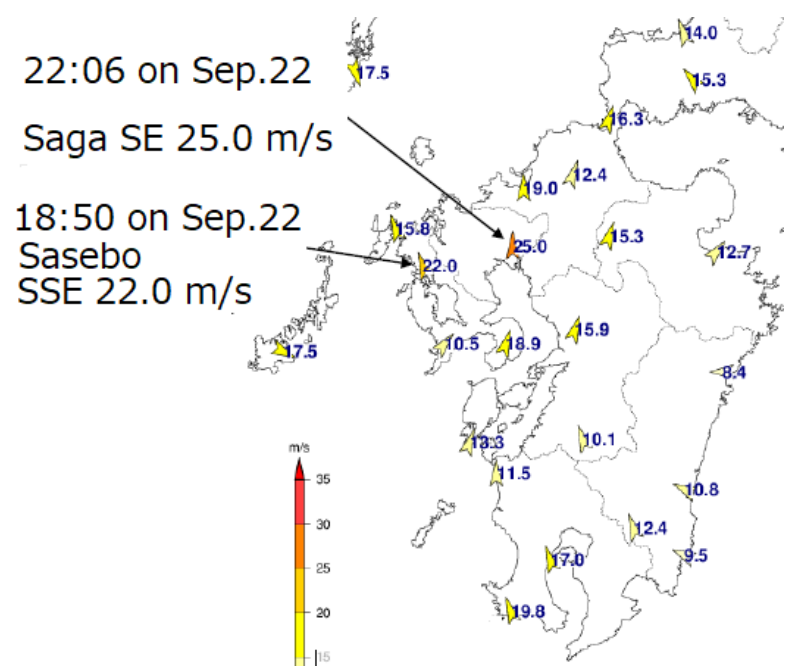

(a) Maximum Wind Speed (3.7.7 22:20 on Sep.22 28.9

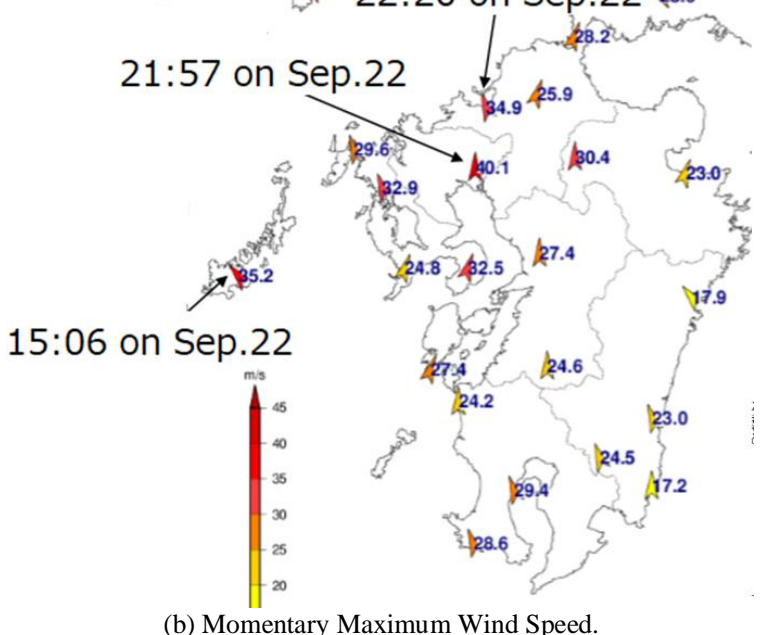

(b) Momentary Maximum Wind Speed.

Fig. 4. Elapsed Time of the Maximum Wind Speed and the Momentary Maximum Wind Speed.

\section{PROPOSED METHOD}

As shown in previous paper, there is the relation between sea salt amount attached to the rice leaves in concern and Normalized Difference Vegetation Index: NDVI derived from remote sensing satellite (Sentinel-2) based visible to near infrared radiometer data as shown in Fig. 5. Therefore, it is possible to estimate vegetation damage by sea salt due to sea breeze by using this relation. Sea breeze damage grade is estimated with degradation of NDVI through a comparison between NDVI before typhoon and after typhoon.

On the other hand, it is hard to estimate vegetation damage by leaf lodging by strong wind due to sea breeze. It, however, is possible to estimate leaf lodging by using back scattering coefficient derived from synthetic aperture radar data which is derived from Sentinel-1A and 1B.

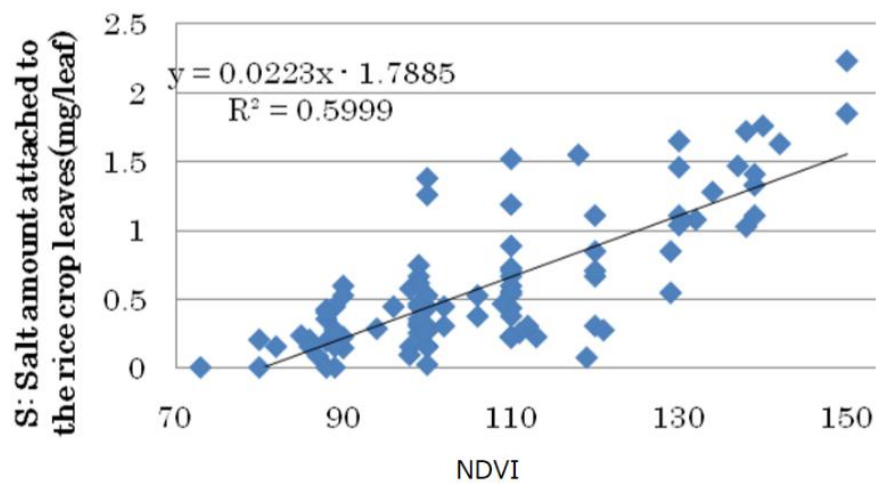

Fig. 5. Relation between Sea Salt Amount Attached to the Rice Leaves in Concern and NDVI Derived from Remote Sensing Satellite based Visible to near Infrared Radiometer Data.

\section{EXPERIMENTS}

\section{A. Intensive Study Area}

Intensive study area of Saga prefecture and northern Kyushu area are shown in Fig. 6(a) and (b), respectively. 25.0 $\mathrm{m} / \mathrm{s}$ of maximum wind speed from the south west direction was observed in Saga prefecture at 22:06 (JST) on 22 September 2019 while $40.1 \mathrm{~m} / \mathrm{s}$ of momentary maximum wind speed from the south was observed at 21:57 (JST) on that day.

As shown in Fig. 6(a), rice paddy fields are situated in the coastal areas in particular, and entire Saga prefecture. In particular, sea breeze, sea salt damage are occurred in the coastal areas and the areas along with rivers also rice lodging is occurred in the rice paddy fields situated in all over the Saga prefecture. Therefore, the intensive study area is selected.

\section{B. Data used}

Sentinel-1 of SAR data is used for detection of oil spill and collapsed area detection. There are two Sentinel-1 satellite, 1A and $1 \mathrm{~B}$. Both of repetition cycle is 12 days. Therefore, it is possible to observe the earth surface every 6 days. Also, there are two polarization of available SAR data, VV and VH (V and $\mathrm{H}$ stands for vertical and horizontal polarization so that $\mathrm{VV}$ means emit $\mathrm{V}$ polarization of Electromagnetic Wave: EM (C band) and receive $\mathrm{V}$ polarization of EM return echo from the earth surface. Spatial resolution of SAR on the ground is $5 \mathrm{~m}$. Table I shows major specification of Sentinel-1 of SAR.

Meanwhile, Sentinel-2 carries $10 \mathrm{~m}$ resolution of visible to short wave infrared radiometer. Table II shows major specification of optical sensor onboard Sentinel-2 Band 12 is Short Wave Infrared SWIR band while band 8 is Near Infrared: NIR band. Also, band 4 is red color band so that Normalized Deviation of Vegetation Index: NDVI and be retrieved with the following equation,

$\mathrm{NDVI}=(\mathrm{B} 8-\mathrm{B} 4) /(\mathrm{B} 8+\mathrm{B} 4)$ 


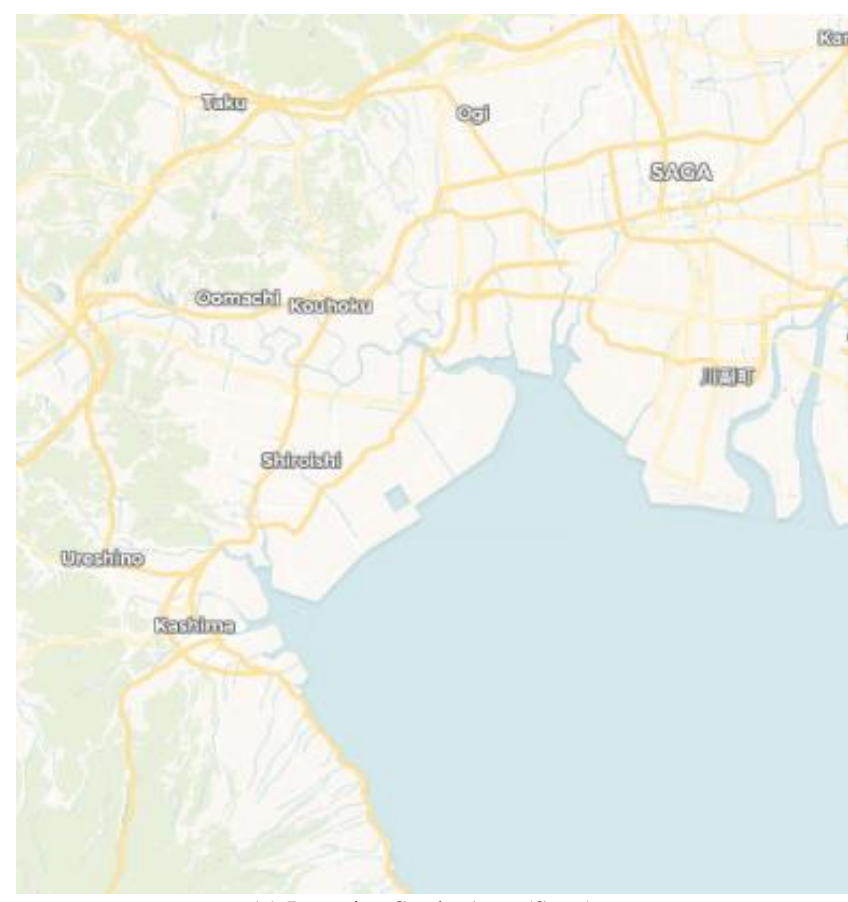

(a) Intensive Study Area (Saga).

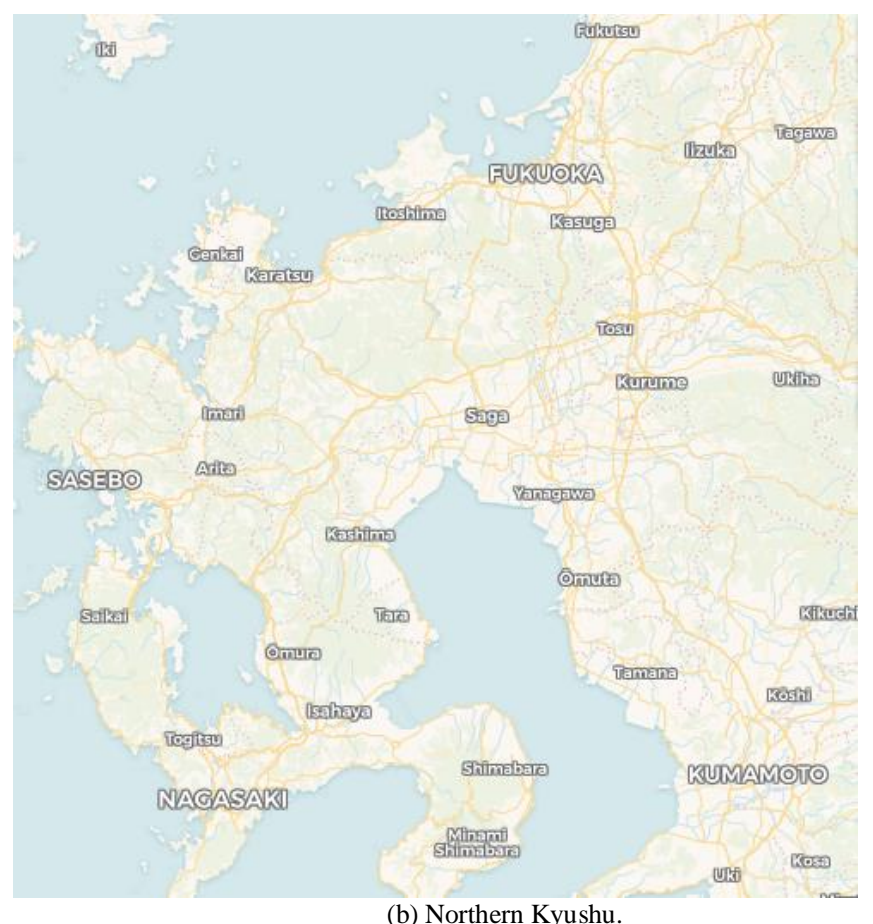

(b) Northern Kyushu.

Fig. 6. Location of Saga Prefecture.

TABLE. I. MAJOR SPECIFICATION OF SENTINEL-1 OF SAR

\begin{tabular}{|l|l|l|l|}
\hline Stripmap & $80 \mathrm{~km}$ & $5 \mathrm{~m} \times 5 \mathrm{~m}$ & HH-HV, VV-VH \\
\hline
\end{tabular}

TABLE. II. MAJOR SPECIFICATION OF OPTICAL SENSOR ONBOARD SENTINEL-2

\begin{tabular}{|l|l|l|}
\hline B1 & $443 \mathrm{~nm}$ & $60 \mathrm{~m}$ \\
\hline B2 & $490 \mathrm{~nm}$ & $10 \mathrm{~m}$ \\
\hline B3 & $560 \mathrm{~nm}$ & $10 \mathrm{~m}$ \\
\hline B4 & $665 \mathrm{~nm}$ & $10 \mathrm{~m}$ \\
\hline B5 & $705 \mathrm{~nm}$ & $20 \mathrm{~m}$ \\
\hline B6 & $740 \mathrm{~nm}$ & $20 \mathrm{~m}$ \\
\hline B7 & $775 \mathrm{~nm}$ & $20 \mathrm{~m}$ \\
\hline B8 & $842 \mathrm{~nm}$ & $10 \mathrm{~m}$ \\
\hline B8a & $865 \mathrm{~nm}$ & $20 \mathrm{~m}$ \\
\hline B9 & $940 \mathrm{~nm}$ & $60 \mathrm{~m}$ \\
\hline B10 & $1375 \mathrm{~nm}$ & $60 \mathrm{~m}$ \\
\hline B11 & $1610 \mathrm{~nm}$ & $20 \mathrm{~m}$ \\
\hline B12 & $2190 \mathrm{~nm}$ & $20 \mathrm{~m}$ \\
\hline
\end{tabular}

Also, SWIR color composite image can be derived from Band 12, Band 8A and Band 4 while false color composite image can be derived from Band 8, 4, and 3 where Band 3 is green color band.

\section{Experimental Results}

Fig. 7(a) and (b) show the false color and NDVI images of the intensive study area acquired at 02:08:20UTC on 14 September 2019 (just before the typhoon \#17).

Although Sentinel-2 observed the intensive study area on 14 of September, the data acquired on 17, 19, 22, 27, 29 of September are covered with clouds. After the typhoon \#17, partially cloudy scene was acquired on 4, 9 and 14 of September. Good Sentinel-2 data were not acquired on 7 and 12 of September. On the other hand, Fig. 8 shows the false color and NDVI images of the intensive study area acquired on 4 of October (just after the typhoon \#17). In the figure of NDVI, color scale is as shown in Fig. 9.

Meanwhile, Fig. 10 shows the false color and NDVI images of the intensive study area acquired on 10 of October.

Mean and standard deviation of false colored image of the paddy fields in the intensive study area acquired on 14 September are 175.15 and 42.73, respectively. Meanwhile, those for 10 October are 149.14 and 45.56, respectively. Therefore, vitality of the rice leaves is degraded by $17.43 \%$ due to the typhoon \#17. In other word, $17.43 \%$ of paddy fields in the intensive study areas are degraded due to sea salt damage and sea breeze as well as rice lodging. Fig. 11 shows subtracted image between the false images between 14 September and 10 October. These red colored areas are damaged areas due to the typhoon \#17.

Table III shows trend of the percentage ratio of the averaged NDVI of the rice paddy fields in the intensive study area derived from Sentinel-2 of satellite imagery data. The ratio is defined as the ratio between the averaged NDVI of September 14 and the other NDVI. The ratio of September 14 (just before the typhoon \#17) is much greater than the others.

The ratio of October 4 (just after the typhoon \#17) is getting down shapely. Then it is going down gradually on October 9 and 14. This is the well-known feature of the sea salt damage of rice leaves. Namely, NDVI is getting down in accordance with elapsed time duration due to sea salts. 

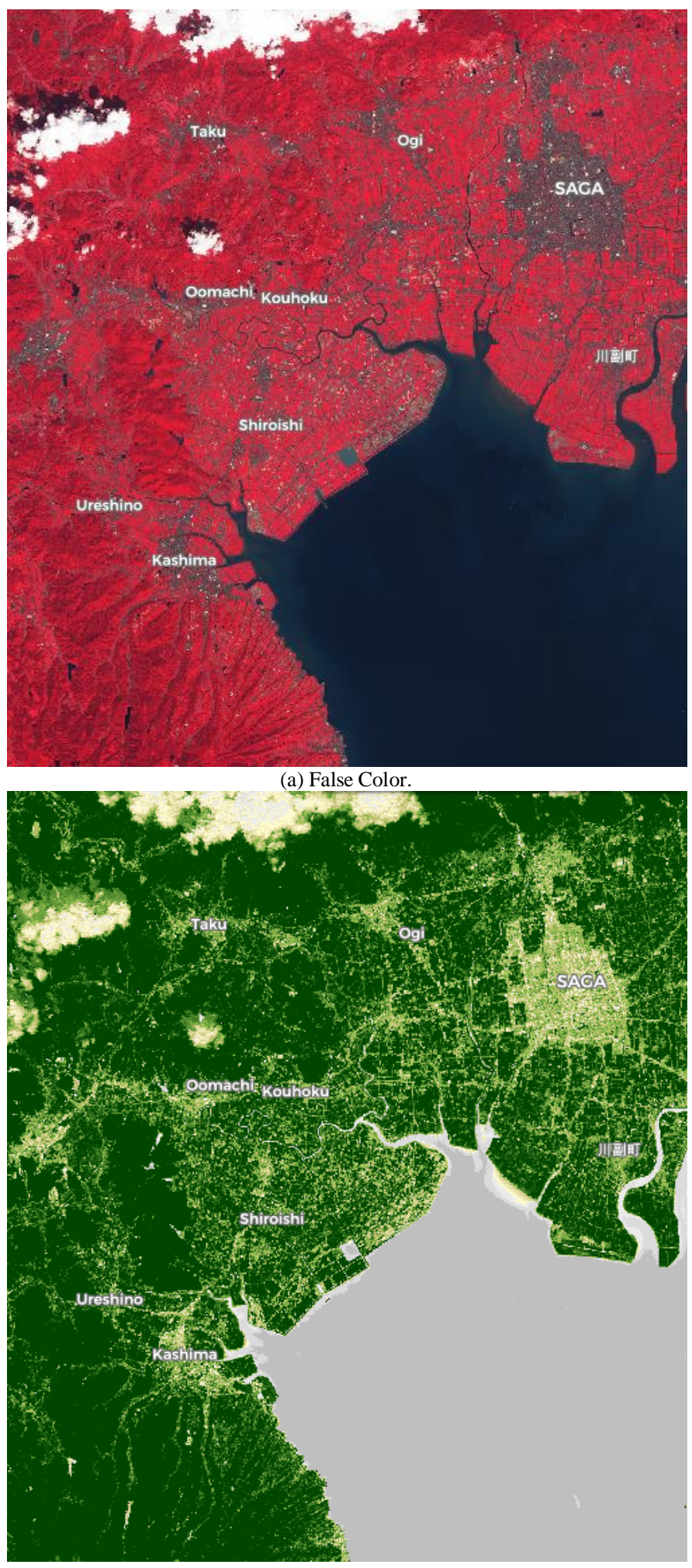

(b) NDVI.

Fig. 7. False Color and NDVI Images of the Intensive Study Area Acquired at 02:08:20UTC on 14 September 2019.

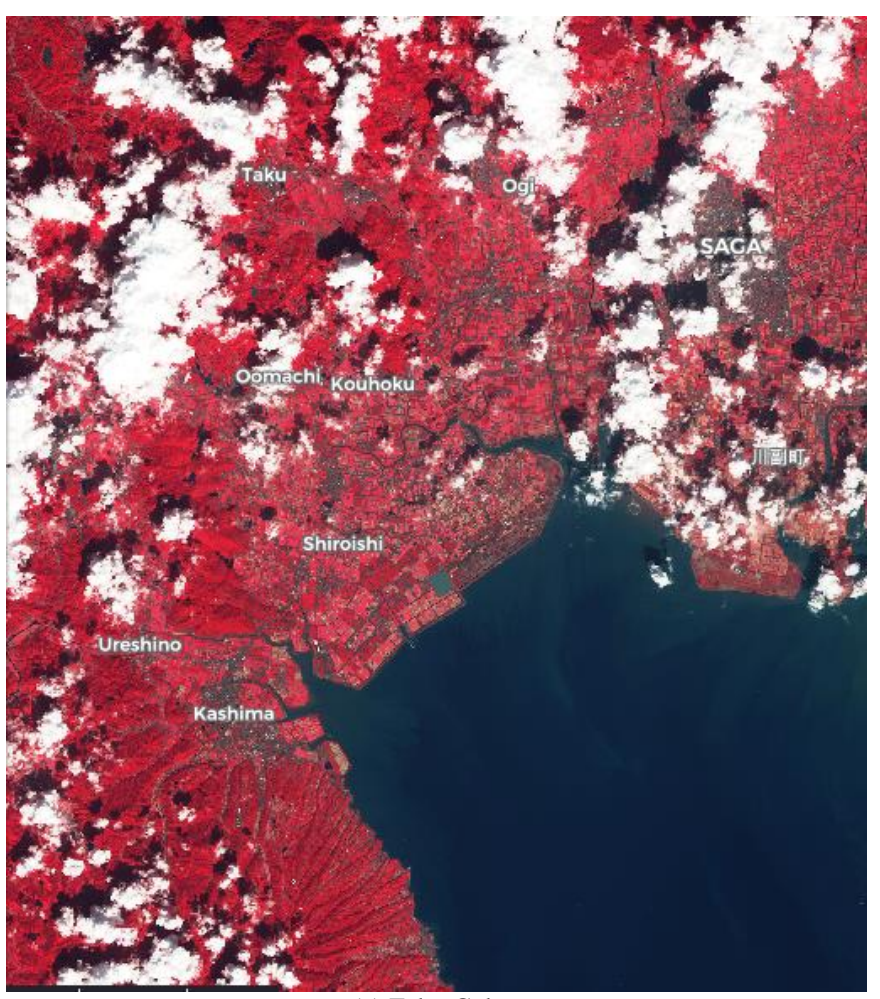

(a) False Color.

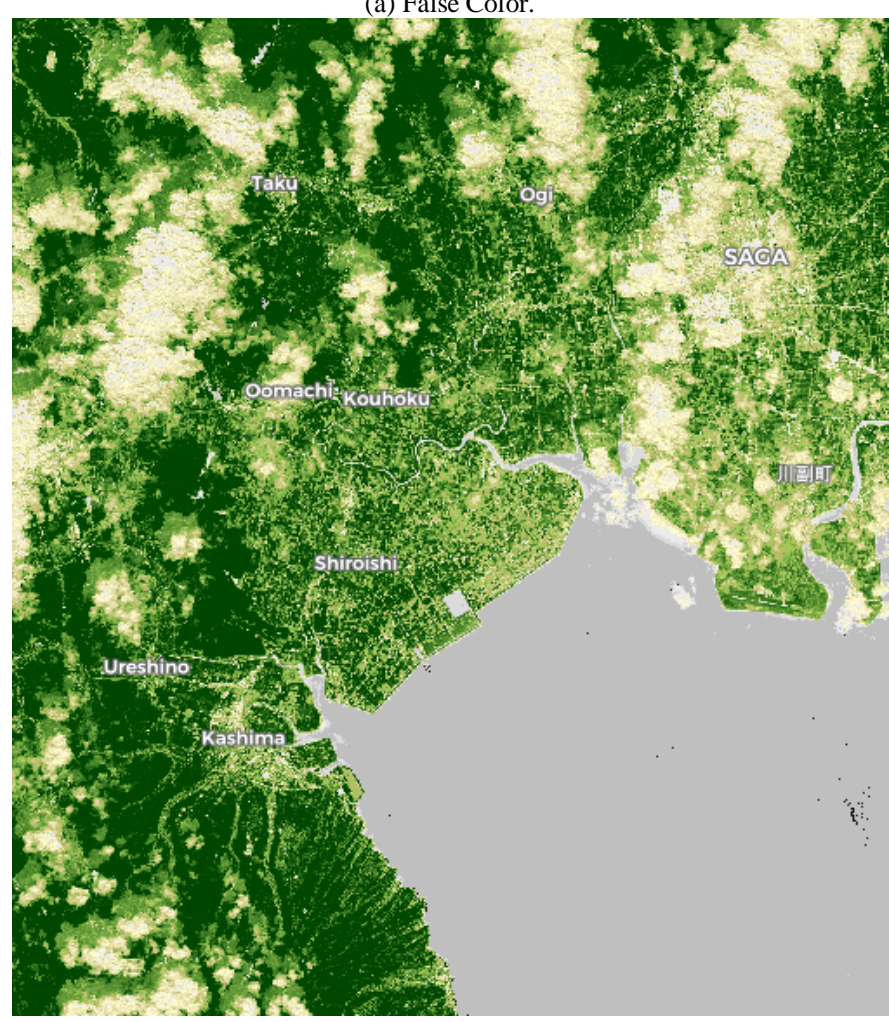

(b) NDVI.

Fig. 8. False Color and NDVI Images of the Intensive Study Area Acquired on 4 of October. 


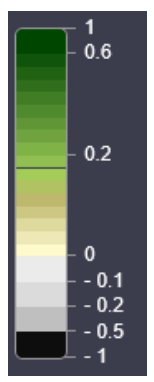

Fig. 9. NDVI Color Scale.

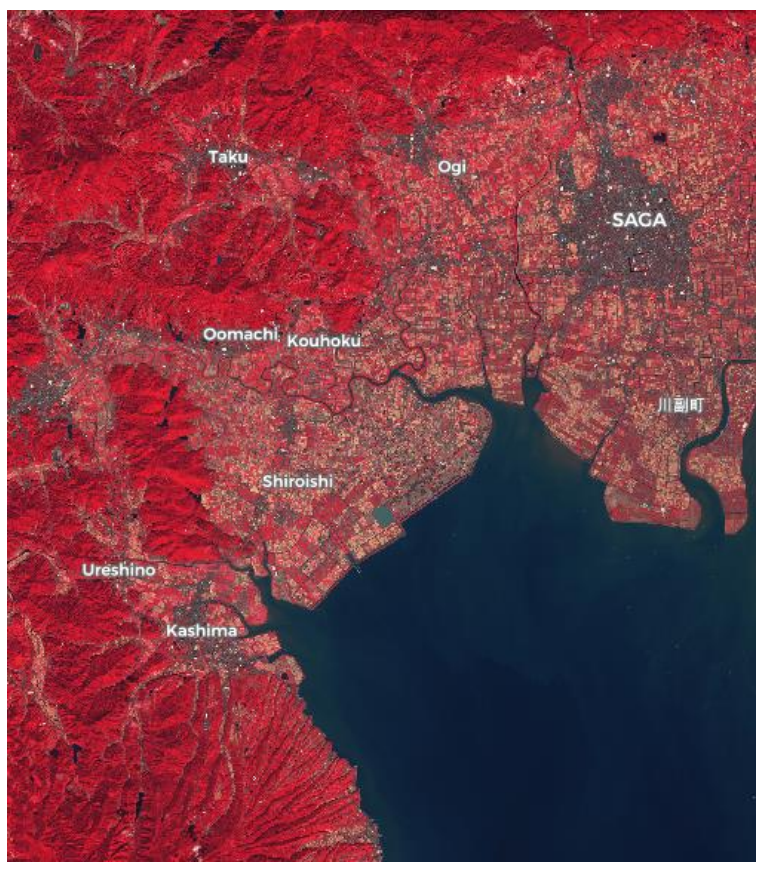

(a)False color

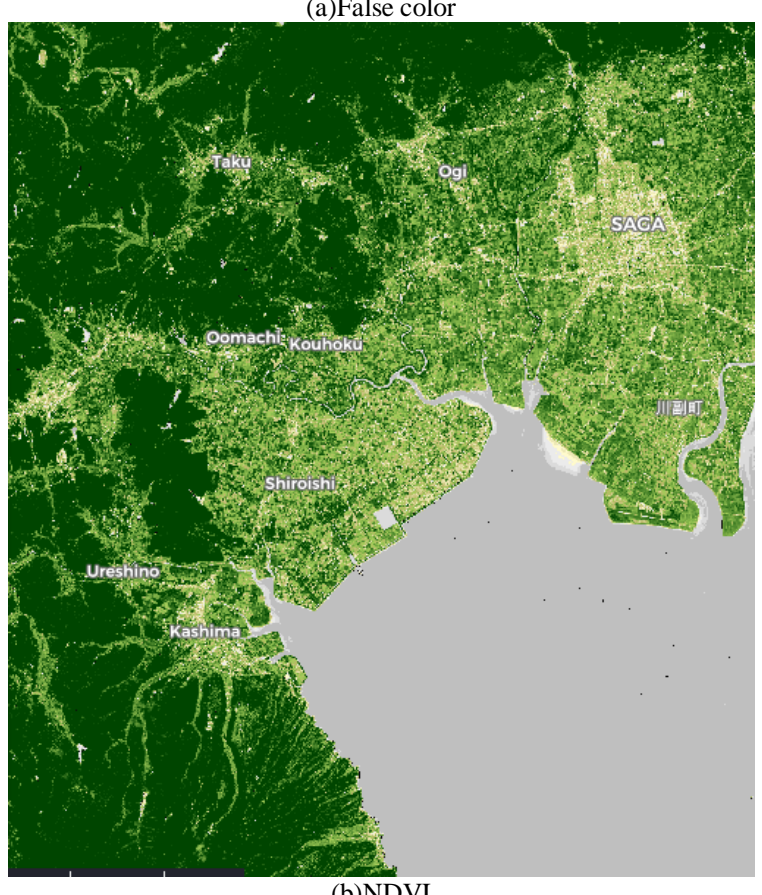

(b)NDVI

Fig. 10. False Color and NDVI Images of the Intensive Study Area Acquired on 10 of October.

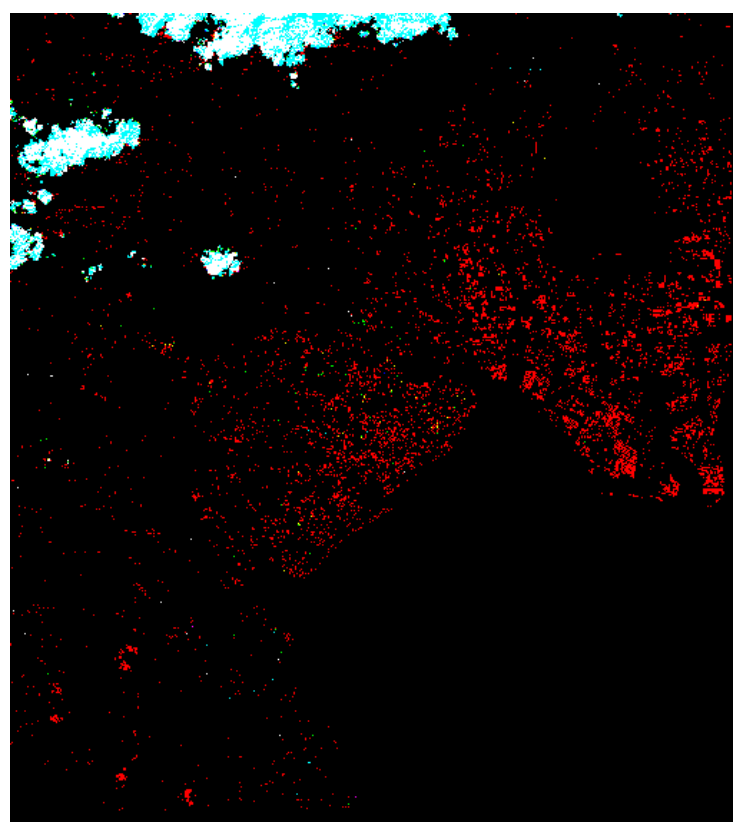

Fig. 11. Subtracted Image between the False Images between 14 September and 10 October.

TABLE. III. TREND OF THE PERCENTAGE RATIO OF THE AVERAGED NDVI OF THE RICE PADDY FIELDS IN THE INTENSIVE STUDY AREA DERIVED FROM SENTINEL-2 OF SATELLITE IMAGERY DATA

\begin{tabular}{|l|l|}
\hline September/14 & - \\
\hline October/4 & $30.99 \%$ \\
\hline October/9 & $34.13 \%$ \\
\hline October/14 & $45.63 \%$ \\
\hline
\end{tabular}

Damaged rice paddy fields are mostly situated in the coastal areas and are partially situated in the entire the intensive study area as well.

In particular, rice lodging can be detected with SAR data because backscattering coefficient of rice lodging areas is decreased theoretically. Fig. 12(a) and (b) shows ortho rectified VV sigma note (back scattered cross section of the earth surface) in unit of decibel of the areas which are acquired on 20 September (just before the typhoon \#17) and 1 October 2019 (just after the typhoon \#17), respectively. Also, Fig. 13 shows the subtracted image between ortho rectified VV sigma note (back scattered cross section of the earth surface) in unit of decibel of the areas which are acquired on 20 September and 1 October.

Mean and standard deviation of the rice paddy fields in the intensive study area are 151.45 and 25.99 for 20 September and are 150.48 and 21.85 for 1 October, respectively. Therefore, $0.64 \%$ of back scattering coefficient decreasing is observed between before and after the typhoon \#17.

Due to the fact that the wind direction in the intensive study are is from south, it is a blowing wind. Therefore, rice lodging is not occurred. It would be significant when the wind direction is from north because it means that a blown down wind. Therefore, rice lodging would occur. It is obvious that $0.64 \%$ is not significant. Therefore, it is true that the rice lodging is not significant at all. 

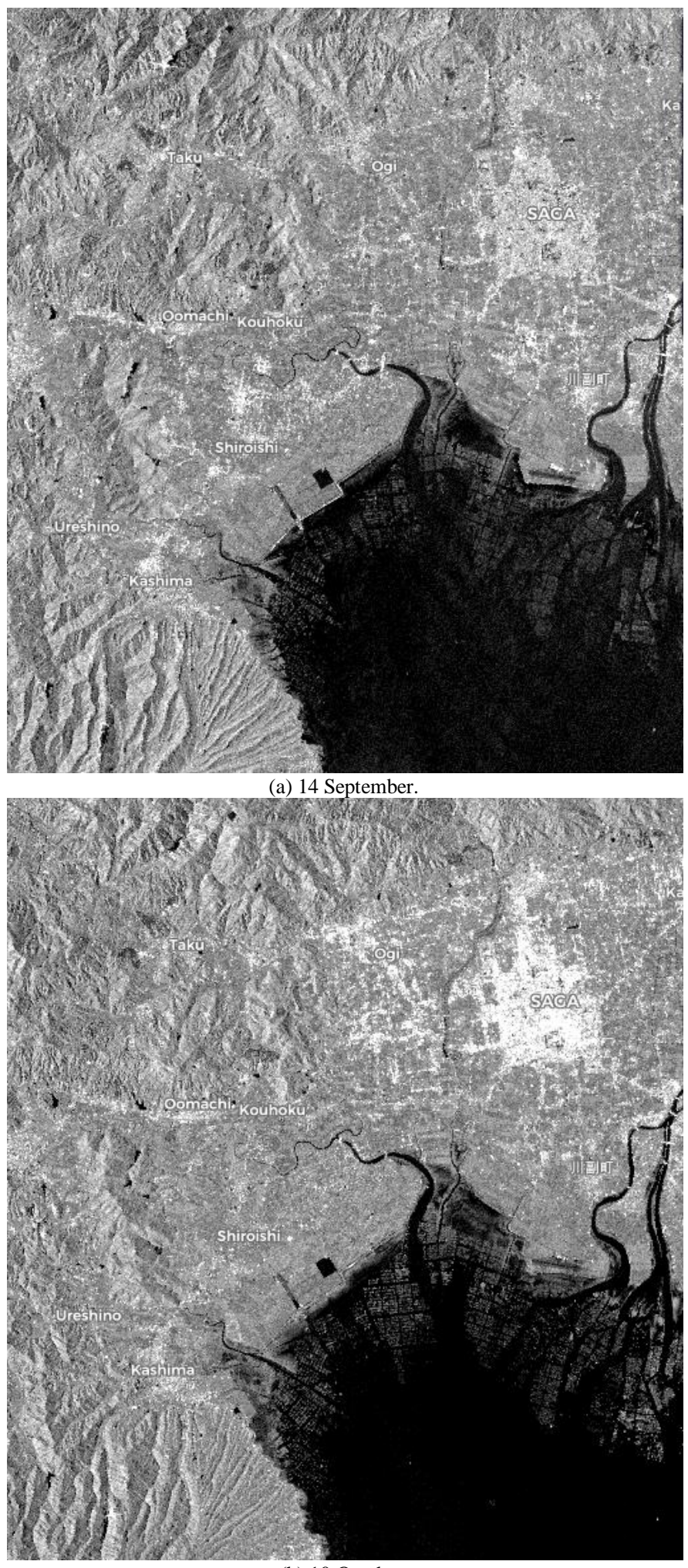

(b) 10 October

Fig. 12. Ortho Rectified VV Sigma Note (Back Scattered Cross Section of the Earth Surface) in unit of Decibel of the Areas.

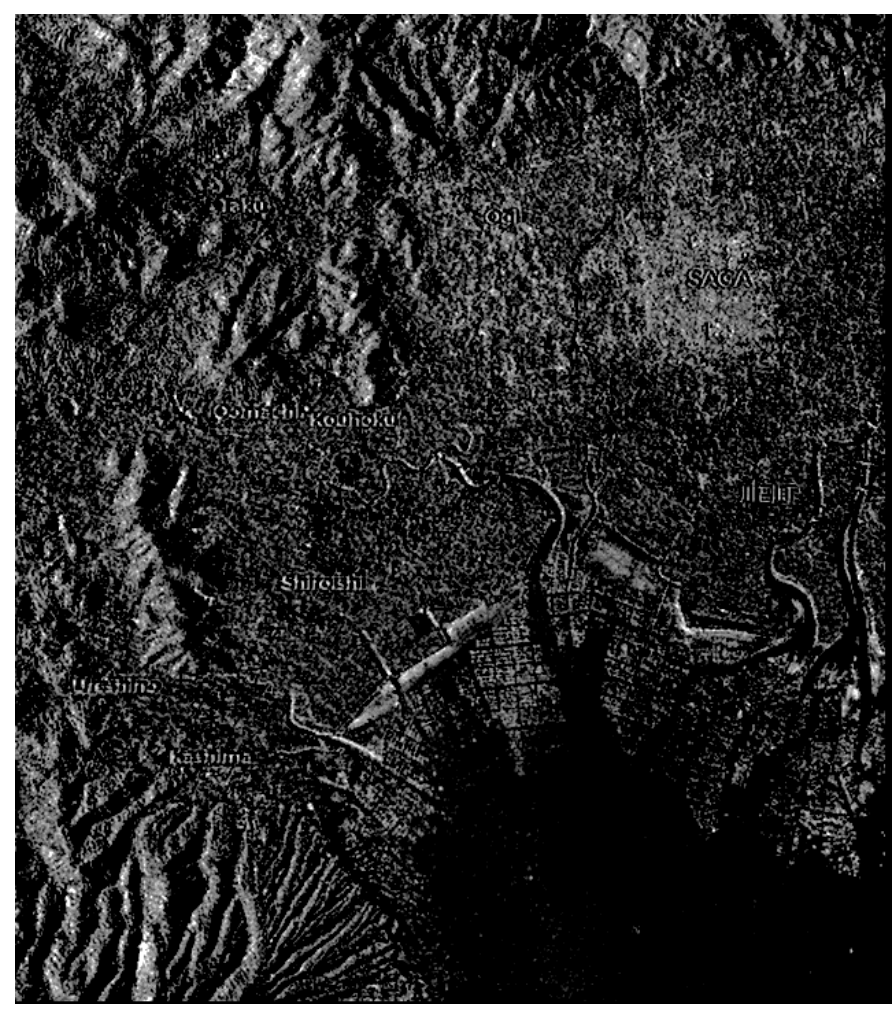

Fig. 13. Subtracted Image between Ortho Rectified VV Sigma Note (Back Scattered Cross Section of the Earth Surface) in unit of Decibel of the Areas which are Acquired on 20 September and 1 October.

\section{CONCLUSION}

Sea breeze and sea salt damage disaster relief using Sentinel of remote sensing satellite data is conducted. Kyushu, Japan had severe storm due to the typhoon \#17 during from 21 September to 23 September 2019. Optical sensor and Synthetic Aperture Radar: SAR onboard remote sensing satellite is used for disaster relief. NDVI and false colored imagery data derived from the Sentinel-1 and 2 data are used for disaster relief. Merits and demerits of the optical sensor and SAR instrument are compared from the disaster relief of point of view. It is found that sea salt damage on rice paddy fields in particular can be relieved by NDVI and false colored imagery data while rice lodging can also be relieved by SAR data.

It is found that vitality of the rice leaves is degraded by $17.43 \%$ due to the typhoon \#17. In other word, $17.43 \%$ of paddy fields in the intensive study areas are degraded due to sea salt damage and sea breeze as well as rice lodging. It is also found that $0.64 \%$ of back scattering coefficient decreasing is observed between before and after the typhoon \#17. It is obvious that $0.64 \%$ is not significant. Therefore, it is true that the rice lodging is not significant at all.

\section{FUTURE RESEARCH WORKS}

Further experimental studies are required for the validation of the proposed method. Also, applicability of the proposed method has to be confirmed through further experiments. 


\section{ACKNOWLEDGMENT}

The author would like to thank Professor Dr. Hiroshi Okumura for his valuable discussions.

\section{REFERENCES}

[1] Kohei Arai, Method for estimation of damage grade and damaged paddy field areas sue to salt containing sea breeze with typhoon using remote sensing imagery data, International Journal of Applied Science, 2, 3, 8492, 2011.

[2] 135. Kohei Arai, Four Dimensional GIS and Its Application to Disaster Monitoring with Satellite Remote Sensing Data, Proceedings of the Conference on GIS and Application of Remote Sensing to Disaster Management, 132-137(1997).

[3] 151. Kohei Arai, The Conference on GIS and Application of Remote Sensing to Disaster Management Four Dimensional GIS and Its Application to Disaster Monitoring with Satellite Remote Sensing Data, Proceedings of the Conference on GIS and Application of Remote Sensing to Disaster Management, 132-137 Greenbelt, Maryland, U.S.A., 1997.

[4] Kohei Arai, URL search engine with text search tools for disaster mitigation, Proceedings of the Asian Disaster Reduction Center R\&D Project Workshop, Mar.3, (2000).

[5] Kohei Arai, Visualization of disaster information derived from Earth observation data, Proceedings of the Asian Disaster Reduction Center R\&D Project Workshop, Aug.31, (2000).

[6] 266. Kohei Arai, ICT technology for disaster mitigation,-Tsunami warning system-, Proceedings of the 1st International Workshop on Knowledge Cluster Systems, 2007.

[7] 318. Kohei Arai, Cellular automata approach for disaster propagation prediction and required data system in GIS representations, Proceedings of the 1st ICSU/WDS Conference - Global Data for Global Science, 2011.

[8] Kohei Arai, Cell based GIS as Cellular Automata for disaster spreading prediction and required data systems, CODATA Data Science Journal, 137-141, 2012.
[9] Kohei Arai, Hiroshi Okumura, Shogo Kajiki, Disaster relief with satellite based synthetic aperture radar data, Proceedings of the SAI Future Technology Conference 2017, No.521, 1026-1029, at Vancouver, 2017.

[10] Kohei Arai, Sentinel 1A SAR Data Analysis for Disaster Mitigation in Kyushu, Kyushu Brunch of the Japanese Society on Remote Sensing, Special Lecture for Young Engineers on Remote Sensing, Nagasaki University, 2018.

[11] Kohei Arai, Sensor network for landslide monitoring with laser ranging system avoiding rainfall influence on laser ranging by means of time diversity and satellite imagery data based landslide disaster relief, International Journal of Applied Sciences, 3, 1, 1-12, 2012.

[12] Kohei Arai, Flooding and oil spill disaster relief using Sentinel of remote sensing satellite data, International Journal of Advanced Computer Science and Applications IJACSA, 10, 12, 290-297, 2019.

\section{AUTHOR'S PROFILE}

Kohei Arai, He received BS, MS and PhD degrees in 1972, 1974 and 1982, respectively. He was with The Institute for Industrial Science and Technology of the University of Tokyo from April 1974 to December 1978 also was with National Space Development Agency of Japan from January, 1979 to March, 1990. During from 1985 to 1987 , he was with Canada Centre for Remote Sensing as a Post Doctoral Fellow of National Science and Engineering Research Council of Canada. He moved to Saga University as a Professor in Department of Information Science on April 1990. He was a councilor for the Aeronautics and Space related to the Technology Committee of the Ministry of Science and Technology during from 1998 to 2000 . He was a councilor of Saga University for 2002 and 2003. He also was an executive councilor for the Remote Sensing Society of Japan for 2003 to 2005 . He is an Adjunct Professor of University of Arizona, USA since 1998. He also is Vice Chairman of the Science Commission "A" of ICSU/COSPAR since 2008 then he is now award committee member of ICSU/COSPAR. He wrote 37 books and published 570 journal papers. He received 30 of awards including ICSU/COSPAR Vikram Sarabhai Medal in 2016, and Science award of Ministry of Mister of Education of Japan in 2015. He is now Editor-in-Chief of IJACSA and IJISA. http://teagis.ip.is.saga-u.ac.jp/index.html 